\title{
Escin induces apoptosis in human renal cancer cells through G2/M arrest and reactive oxygen species-modulated mitochondrial pathways
}

\author{
SHEAU-YUN YUAN ${ }^{1,2}$, CHEN-LI CHENG ${ }^{1}$, SHIAN-SHIANG WANG ${ }^{1,3}$, HAO-CHUNG HO ${ }^{1}$, KUN-YUAN CHIU ${ }^{1}$, \\ CHUAN-SHU CHEN ${ }^{1}$, CHENG-CHE CHEN ${ }^{1}$, MING-YUH SHIAU $^{2 *}$ and YEN-CHUAN OU ${ }^{1,4^{*}}$ \\ ${ }^{1}$ Division of Urology, Department of Surgery, Taichung Veterans General Hospital, Taichung 40705; \\ ${ }^{2}$ Department of Nursing, Hung Kuang University, Taichung 43302; ${ }^{3}$ School of Medicine, \\ Chung Shan Medical University, Taichung 40201; ${ }^{4}$ Department of Education and Research, \\ Taichung Veterans General Hospital, Taichung 40705, Taiwan, R.O.C.
}

Received May 6, 2016; Accepted July 1, 2016

DOI: $10.3892 /$ or.2017.5348

\begin{abstract}
Escin, a natural pentacyclic triterpenoid compound, exhibits antitumor effects on various types of human cancer cells, but its effect on human renal cancer cells has not been fully elucidated. In the present study, we demonstrated that escin elicits cytotoxic effects on human renal cancer cells (786-O and Caki-1) in a dose-dependent manner, as determined by MTT assay. Escin induced G2/M arrest, and then increased the sub-G1 population, Annexin V binding, activation of caspase-9/-3, cleavage of poly(ADP-ribose) polymerase (PARP) and Bax protein. Escin also decreased the anti-apoptotic protein levels of Bcl-2, X-linked inhibitor of apoptosis protein and survivin. In addition, escin induced reactive oxygen species (ROS) generation, leading to mitochondrial membrane potential dysfunction and inducing apoptosis in 786-O renal cancer cells, which were suppressed by antioxidants, such as NAC. Collectively, our results suggest that escin induces apoptosis via the intrinsic-mitochondrial apoptosis pathway through G2/M arrest and ROS generation in human renal cancer cells. Escin appears to have potential
\end{abstract}

Correspondence to: Dr Ming-Yuh Shiau, Department of Nursing, Hung Kuang University, 1018 Sec. 6, Taiwan Boulevard, Shalu, Taichung 43302, Taiwan, R.O.C.

E-mail: ming@sunrise.hk.edu.tw

Dr Yen-Chuan Ou, Division of Urology, Department of Surgery, Taichung Veterans General Hospital, Taichung 40705, Taiwan, R.O.C.

E-mail: ycou@vghtc.gov.tw

"Contributed equally

Key words: escin, apoptosis, renal cell carcinoma, reactive oxygen species, G2/M arrest as a clinically useful chemotherapeutic agent for human renal cancer.

\section{Introduction}

Renal cell carcinoma (RCC) is the most common malignant kidney tumor with a rising annual incidence rate, and currently accounts for $\sim 2-4 \%$ of all malignant adult diseases worldwide (1). It is categorized according to histological subtypes: clear cell, papillary, chromophobe and collecting duct RCC (2). Clear cell RCC (cc-RCC) accounts for $>90 \%$ of all RCC cases and the loss of the von Hippel-Lindau (VHL) tumor-suppressor gene in the biallellic loci occurs in 50-60\% of RCC cases (3). Currently, there are several therapeutic approaches for RCC, including radical nephrectomy, conventional chemotherapy and immunotherapy. However, $40 \%$ of patients are resistant to conventional chemotherapy and irradiation. Such patients may develop systemic recurrence and together with the resultant high toxicity and low response therapy failure is inevitable. Thus, the 2-5-year survival rates are less than $20 \%$ (4-6). Novel therapeutic strategies may be available, but they are prone to side-effects such as fatigue, nausea, hypertension, proteinuria and neutropenia which need to be managed. Therefore, an effective and tolerable therapy for RCC is urgently needed.

Plant extracts have been used as traditional medicines since antiquity $(7,8)$. They continue to be used by traditional medicine practitioners and are being explored in clinical research as potential anticancer agents, which offer the additional advantage of being less expensive than conventional drugs. The evaluation of certain naturally occurring phytochemicals that can reduce the risk and inhibit the progression of cancer would be useful as it may lead to the identification of certain candidate plant extracts with the potential for development as therapeutic cancer drugs. For example, the saponin products isolated from the seeds of the horse chestnut Aesculus hippocastanum (Europe), Aesculus turbinata Blume (Japan) and Aesculus chinensis var. wilsonii (Rehder) (China) which are known as escin and exist in 
either $\alpha$ or $\beta$ form, were found to have potential application in cancer treatments (9-11). $\beta$-aescin or escin (Fig. 1A) is a pentacyclic triterpenoid compound with anti-edematous (e.g., postoperative edema) (12), anti-chronic venous insufficiency (CVI) and anti-hemorrhoid $(13,14)$ properties.

Moreover, escin also displays anti-inflammatory activity $(15,16)$ (e.g., carrageenan-induced hind paw edema in an animal model), ex vivo rat aortic disk angiogenesis, as well as endothelial cell proliferation, migration and apoptosis (17), hypoglycemic (18), anti-obesity (19) and anti-secretory effects in a rat model (20). Due to its versatile properties, escin has been considered as a potential candidate chemotheraputic agent for the treatment of cancer (9-11). Escin has been shown to induce apoptosis in several types of human tumor cells, such as pancreatic cancer cells (21), acute leukemia Jurkat T cells (22), leukemia HL-60 cells (23), chronic myeloid leukemia K562 cells (24), cholangiocarcinoma cells (25), hepatoma cells (26) and colon cancer cells (27). In addition, escin was reported to induce apoptosis in some of these tumor cells (hepatoma and colon cancer cells) by causing cell cycle arrest at the G1/S phase mediated by $\mathrm{p} 21^{\mathrm{WAF} 1 / \mathrm{CIP} 1}$ upregulation, which is associated with the reduced level of cyclin E/ Cdk2 (26,27). However, the molecular mechanisms by which escin induces apoptosis in tumor cells remain to be defined.

In the present study, we demonstrate for the first time that escin effectively induces apoptosis in human renal cancer cells. We also provide evidence to suggest that the intrinsicmitochondrial apoptosis pathway is mainly responsible for escin-induced apoptosis in these tumor cells.

\section{Materials and methods}

Cell culture and reagents. Human renal cancer cell lines (786-O and Caki-1) were purchased from Bioresource Collection and Research Center (BCRC; Hsinchu, Taiwan) and American Type Culture Collection (ATCC; Manassas, VA, USA), respectively. The cell lines were cultured in RPMI or McCoy's medium and supplemented with $10 \%$ fetal bovine serum (FBS) (Gibco, Gaithersburg, MD, USA) and 1\% antibiotic antimycotic solution. Cells were incubated at $37^{\circ} \mathrm{C}$ with $5 \% \mathrm{CO}_{2}$. Escin was purchased from Sigma-Aldrich Co. (St. Louis, MO, USA). Escin was prepared by dissolving the lyophilized powder in dimethyl sulfoxide (DMSO) to a final concentration of $100 \mathrm{mmol} / \mathrm{l}$. The stock solution was stored at $-20^{\circ} \mathrm{C}$ until use.

Cytotoxicity assay. The cytotoxic effects of escin on renal cancer cell lines were assessed with the 3-(4,5-dimethylthiazol-2-yl)-2,5-diphenyltetrazolium bromide (MTT) assay (Sigma-Aldrich Co.). The cell lines were seeded onto 24-well plates and treated with various concentrations of escin for 24 , 48 , and $72 \mathrm{~h}$. After incubation for the indicated periods, the medium was removed, and $200 \mu 1$ of $1 \mathrm{X}$ MTT solution was added to each well for $4 \mathrm{~h}$. The medium was aspirated and the formazan product in the cells was solubilized by adding DMSO. An aliquot of $150 \mu \mathrm{l}$ was measured using a microplate autoreader (L225-0137; PerkinElmer, Taipei, Taiwan) at the wavelength of $540 \mathrm{~nm}$. The $\mathrm{IC}_{50}$ values with dose-dependent curves were calculated by linear interpolation and carried out in triplicates.
Cell cycle analysis. Propidium iodide (PI) staining and flow cytometry were used to perform cell cycle analysis. First, $1 \times 10^{6} 786-\mathrm{O}$ cells were seeded on $10 \mathrm{~cm}$ dishes for $24 \mathrm{~h}$. The cells were collected after trypsinization and washed with ice-cold phosphate-buffered saline (PBS), fixed and permeabilized with $70 \%$ ethanol at $-20^{\circ} \mathrm{C}$ overnight. The next day, after the cells were washed with ice-cold PBS, they were incubated with PI staining solution $(0.2 \mathrm{mg} / \mathrm{ml}$ RNase, $20 \mu \mathrm{g} / \mathrm{ml}$ PI and $0.1 \%$ Triton $\mathrm{X}-100$ ) for $30 \mathrm{~min}$ at room temperature in the dark. Data were collected using a flow cytometer (BD FACSCalibur; BD Biosciences, San Jose, CA, USA) and data were analyzed with WinMDI software (version 2.9). All experiments were performed in triplicate and 10,000 events were counted for each sample.

Annexin V assay. The BioVision Annexin V-FITC apoptosis detection kit was used for the apoptosis assay (BioVision Inc., Milpitas, CA, USA). First, 786-O cells were seeded onto $10-\mathrm{cm}$ dishes for $24 \mathrm{~h}$ and then exposed to different doses of escin for $16 \mathrm{~h}$. Cells were harvested by trypsinization, washed twice with PBS, and resuspended in $500 \mu 1$ of binding buffer. Cell suspensions were then incubated with $5 \mu \mathrm{l}$ of Annexin V-FITC and $5 \mu \mathrm{l}$ of PI for $10 \mathrm{~min}$ at room temperature in the dark. The cells were immediately evaluated by flow cytometry (FACSCalibur; Becton-Dickinson, San Jose, CA, USA).

Western blot analysis. Renal cancer cells $\left(1 \times 10^{6}\right)$ were seeded in $10-\mathrm{cm}$ culture dishes overnight and treated with the indicated concentrations of escin for $24 \mathrm{~h}$. The cells were harvested, washed twice in PBS, and lysed for $30 \mathrm{~min}$ at $4^{\circ} \mathrm{C}$ with ice-cold RIPA buffer (1\% NP-40 in $150 \mathrm{mM} \mathrm{NaCl}$ ), $50 \mathrm{mM}$ Tris ( $\mathrm{pH} 7.5)$ and $2 \mathrm{mM}$ EDTA. Protein concentrations were measured using the Bradford protein assay. Equal amounts of protein were loaded on $10-15 \%$ sodium dodecyl sulphate-polyacrylamide gel electrophoresis (SDS-PAGE) gels, transferred to polyvinylidene difluoride (PVDF) membranes, and blocked with 5\% non-fat milk in Tris-buffered saline with $0.5 \%$ Tween-20 (TBST) buffer (20 mM Tris-HCl, $120 \mathrm{mM}$ $\mathrm{NaCl}, 0.1 \%$ Tween-20) for $1 \mathrm{~h}$. The membranes were incubated with various primary antibodies against cdc-2 (GeneTex, Inc., Irvine, CA, USA), Bcl-2, Bcl-xL, Bax, caspase-3 and -9, poly(ADP-ribose) polymerase (PARP) $(1: 1,000$; Cell Signaling Technology, Boston, MA, USA) and cyclin B1, caspase-8 (p18), Fas, FasL, FADD, $\beta$-actin and GAPDH (1:1,000; Santa Cruz Biotechnology, Santa Cruz, CA, USA) at $4^{\circ} \mathrm{C}$ overnight. After washing, the blots were incubated with HRP-labelled secondary antibodies for $2 \mathrm{~h}$. The signals of the blots were then developed using the enhanced chemiluminescence (ECL) system and analyzed with the LAS3000 system (Fujifilm, Tokyo, Japan).

Mitochondrial membrane potential assay. Mitochondrialspecific cationic dye JC-1 (Invitrogen, Carlsbad, CA, USA), which undergoes potential-dependent accumulation in the mitochondria, was used. When the mitochondrial membrane potential $(\Delta \Psi \mathrm{m})$ is below $120 \mathrm{mV}, \mathrm{JC}-1$ is monomeric and emits green light $(540 \mathrm{~nm})$ following excitation with blue light $(490 \mathrm{~nm})$. At membrane potentials $>120 \mathrm{mV}$, JC-1 monomer aggregates and emits red light $(590 \mathrm{~nm})$ following excitation 

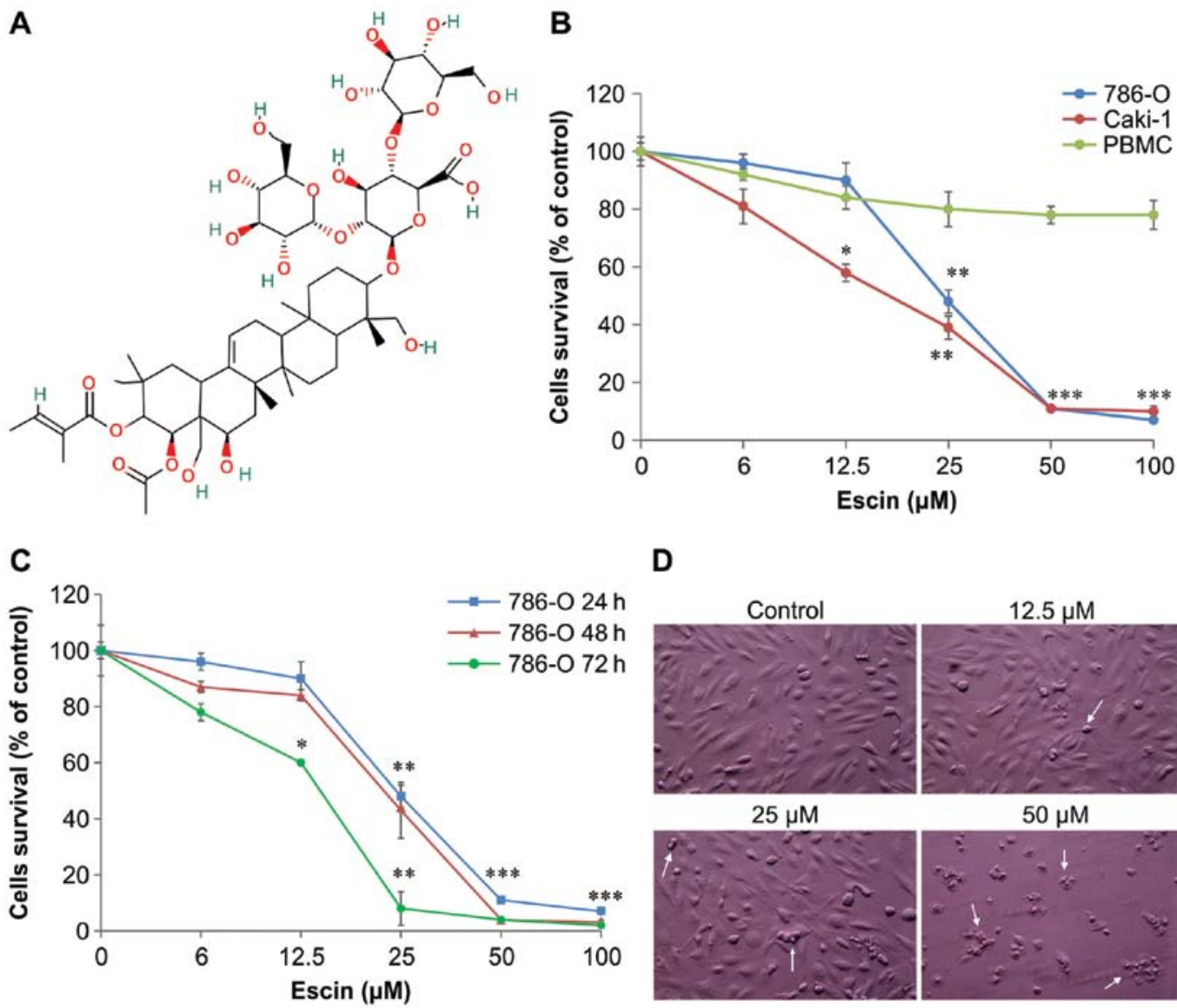

D
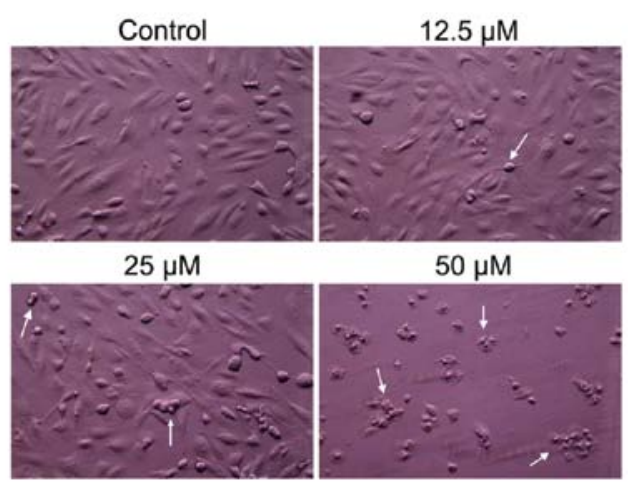

Figure 1. Effect of escin on the cell survival of human renal cancer 786-O and Caki-1 cells and normal human peripheral blood mononuclear cells (PBMCs). (A) The chemical structure of escin. (B) 786-O, Caki-1 and PBMCs were seeded at a density of $2 \times 10^{4}$ cells/well and then treated with escin $(0,6,12.5,25,50$ and $100 \mu \mathrm{M}$ ) or a vehicle-only control for $24 \mathrm{~h}$. The MTT assay (described in 'Materials and methods') was used to quantify cell viability. (C) 786-O cells were also treated with the same concentrations of escin for 24,48 and $72 \mathrm{~h}$, and then cell viability was assessed by the MTT assay. In (B) and (C), data points and error bars represent the mean and standard deviation (SD) of three experiments. Statistical significance ${ }^{*} \mathrm{p}<0.05,{ }^{* * *} \mathrm{p}<0.01,{ }^{* * *} \mathrm{p}<0.001$ as compared with control. (D) Effect of escin on the morphology of 786-O cells. 786-O cells were treated with control (vehicle only), $12.5,25$ and $50 \mu \mathrm{M}$ escin for $24 \mathrm{~h}$. Cells were viewed by phase contrast microscopy and photographed at a magnification of x 200 . The white arrows indicate apoptotic cells.

with green light $(540 \mathrm{~nm})$. For the assay, the cells were seeded onto 6-well plates and treated with various concentrations of escin for $24 \mathrm{~h}$, followed by staining with $5 \mu \mathrm{M} \mathrm{JC}-1$ for $30 \mathrm{~min}$ at $37^{\circ} \mathrm{C}$. Fluorescence was monitored with a fluorescence plate reader at wavelengths of $490 \mathrm{~nm}$ (excitation)/540 nm (emission) and $540 \mathrm{~nm}$ (excitation)/590 nm (emission). Changes in the $\Delta \Psi \mathrm{m}$ were indicated by changes in the ratio of intensities between the measurements at test wavelengths of $590 \mathrm{~nm}$ (red) and $540 \mathrm{~nm}$ (green).

Detection of reactive oxygen species (ROS). A flow cytometric assay of intracellular ROS, which can trigger apoptosis, using dihydroethidium (DHE) (Setareh Biotech LLC, Eugene, OR, USA), a fluorescent superoxide indicator, was previously described (28-31). In the present study, 786-O cells were treated with $0-100 \mu \mathrm{M}$ escin for $24 \mathrm{~h}$. Subsequently, these cells were incubated with $2 \mu \mathrm{M} \mathrm{DHE}$ in serum-free medium at $37^{\circ} \mathrm{C}$ for $15 \mathrm{~min}$, washed once with serum-free medium, and then centrifuged at $450 \mathrm{x}$ g to remove extracellular DHE. Finally, the cells were analyzed by flow cytometry.

Statistical analysis. Experiments were performed three times and the data are presented as mean \pm SD. Student's t-test was carried out to assess the statistical differences. $\mathrm{p}<0.05$ was considered to indicate a statistically significant result.

\section{Results}

Escin exhibits cytotoxic effects on human renal cancer 786-O and Caki-1 cells. To determine the cytotoxic effect of escin on human renal cancer cells, 786-O and Caki-1 cells were treated with several concentrations of escin (12.5-100 $\mu \mathrm{M})$ for 24,48 and $72 \mathrm{~h}$. Normal human peripheral blood mononuclear cells (PBMCs) (as normal control cells) were treated with the indicated concentrations of escin for $24 \mathrm{~h}$. Cell viability of these treated cells was then determined using the MTT assay. As shown in Fig. 1B and C, after 24 h, escin markedly reduced the viability of the 786-O and Caki- 1 cells in a concentration-dependent manner with $\mathrm{IC}_{50}$ values of $40.6 \pm 1.2$ and $35.0 \pm 0.8 \mu \mathrm{M}$, respectively. The $\mathrm{IC}_{50}$ values of escin were $40.6 \pm 1.2,35.4 \pm 0.5$ and $26.2 \pm 0.5 \mu \mathrm{M}$ in the $786-\mathrm{O}$ cells at 24 , 48 and $72 \mathrm{~h}$, respectively. In contrast, PBMCs treated with escin for $24 \mathrm{~h}$ exhibited $>75 \%$ cell survival (Fig. 1B). At the concentration of $50 \mu \mathrm{M}$ escin, marked morphological changes such as shrinkage and rounding were noted in the 786-O cells (Fig. 1D). This corroborated the results from the MTT 
A
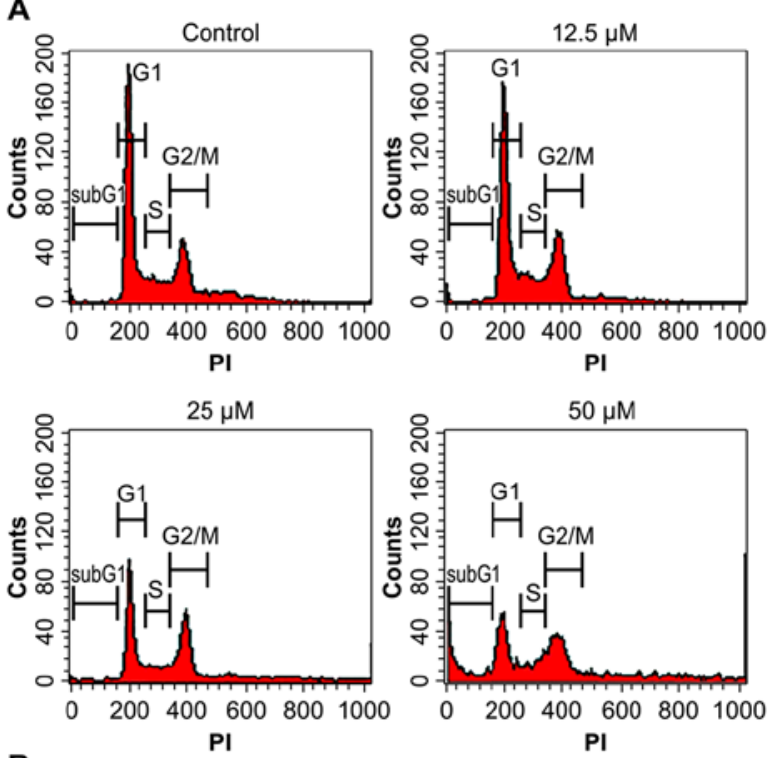

B
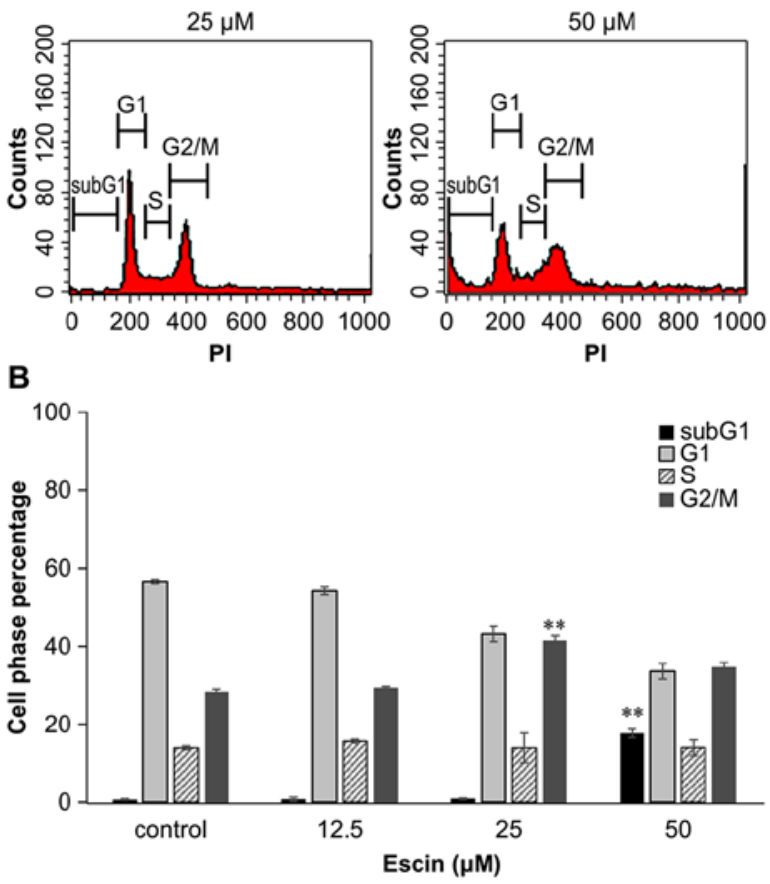

C

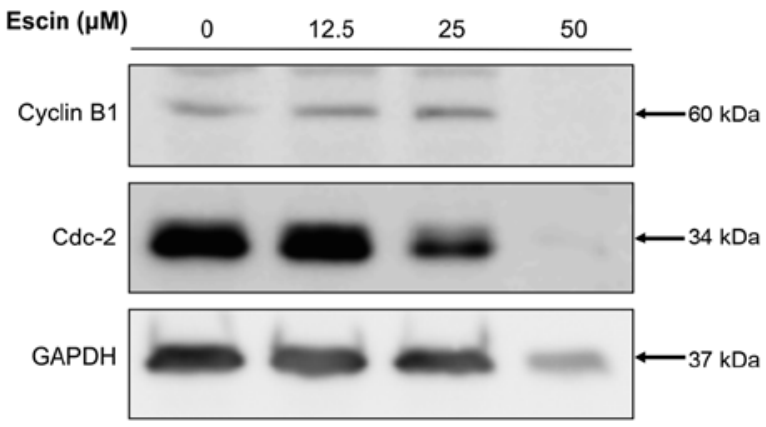

Figure 2. Cell cycle and cell cycle regulatory protein expression analyses in escin-treated 786-O cells. Cells were treated with $0,12.5,25$ and $50 \mu \mathrm{M}$ escin for $24 \mathrm{~h}$. (A) Cells were stained with propidium iodide (PI), and were then analyzed by flow cytometry. (B) The percentages of cells in sub-G1 and $\mathrm{G} 2 / \mathrm{M}$ phase were estimated. The values presented are the mean $\pm \mathrm{SD}$ $(n=3)$ from three independent experiments. Statistical significance ${ }^{* *} \mathrm{p}<0.01$ as compared with the vehicle control-treated cells. (C) Cells were treated with the indicated concentrations of escin for $24 \mathrm{~h}$. Proteins $(50 \mu \mathrm{g})$ from each sample were resolved on $12 \%$ SDS-PAGE and western blotting was performed by immunoblotting with cyclin B1, cdc-2 and GAPDH antibodies.

assay (Fig. 1B and C). Taken together, these results suggest that escin induces cell death or apoptosis.

Escin induces cell cycle G2/M arrest in 786-O cells. To elucidate the underlying mechanism of escin-induced cell death, we analyzed the distribution of the cell cycle in 786-O cells treated with several concentrations of escin for $24 \mathrm{~h}$. As shown in Fig. 2A and B, the mean percentage of sub-G1 cells, which is an indicator of cell death, in 786-O cells treated with the higher tested concentration $(50 \mu \mathrm{M})$ of escin $(17.7 \pm 0.7 \%)$ was significantly higher than that in the untreated cells $(0.7 \pm 0.02 \%)$ $(\mathrm{p}<0.01)$. In addition, the percentage of cells in the $\mathrm{G} 2 / \mathrm{M}$ transition was significantly higher in 786-O cells treated with $25 \mu \mathrm{M}$ escin $(41.6 \pm 2 \%)$ than in untreated cells $(28.3 \pm 1.1 \%)$ $(\mathrm{p}<0.01)$. The levels of $\mathrm{cdc}-2$ protein were decreased relative to the internal control of GAPDH in the cells treated with $25 \mu \mathrm{M}$ escin, but there were no significant changes in cyclin B1 protein levels following treatment with $25 \mu \mathrm{M}$ escin (Fig. 2C). These results suggest that escin induces cell cycle $\mathrm{G} 2 / \mathrm{M}$ arrest in 786-O cells.

To elucidate the type of cell death caused by escin, we stained escin-treated 786-O cells with Annexin V-FITC and PI to define apoptosis and necrosis, respectively. The percentage of early and late apoptotic, and necrotic cells in the 786-O cell line increased in a concentration-dependent manner (Fig. 3A). At the highest tested concentration of escin, early apoptosis occurred in $77.5 \%$ of the 786-O cells compared to the internal control (4.5\%) in a concentration-dependent manner (Fig. 3A). Thus, the percentages of live, early apoptotic and late apoptotic cells were calculated and subjected to statistical analysis (Fig. 3B). These results indicate that escin induced apoptosis in the 786-O cells.

Escin induces caspase-dependent apoptosis in 786-O cells. Caspases, such as caspase- $9-8$ and $-3 / 7$, can be activated by either an intrinsic mitochondrial-mediated pathway or an extrinsic death receptor-mediated pathway (32). Activated caspases cause cleavage of PARP, which is a marker of apoptosis. Thus, to determine whether escin induces apoptosis through the intrinsic or extrinsic pathway, we performed western blot analysis of the pro-form and cleaved forms of caspase-8, -9 and -3, and PARP. As illustrated in Fig. 3C, 786-O cells treated with indicated concentrations of escin for $24 \mathrm{~h}$ expressed elevated levels of the cleaved forms of caspase-9 and -3 , and PARP. It is important to note that the protein level of caspase-3 in $50 \mu \mathrm{M}$ escin-treated $786-\mathrm{O}$ cells was not detected. We reasoned that many cells treated with $50 \mu \mathrm{M}$ escin may be dead and detach from the wells. In addition, the cleaved caspase- 3 protein $(17 \mathrm{kDa})$, which is the smallest proteins among all caspase-cleaved protein molecules, is easily further degraded and may not be detected by western blot analysis. However, the cleaved caspase- 8 protein level (molecular mass; $18 \mathrm{kDa}$ ) was not detected among the concentrations of escin used to treat the cells (Fig. 3C). These results suggest that escin induced intrinsic-pathway apoptosis in these renal cancer cells.

Escin induces mitochondrial-mediated apoptosis in 786-O cells. To confirm that escin induces intrinsic apoptosis, we determined the effect of escin on the mitochondrial membrane potential $(\Delta \Psi \mathrm{m})$ in $786-\mathrm{O}$ cells. Loss of $\Delta \Psi \mathrm{m}$ is a hallmark of intrinsic apoptosis, since it is associated with the release of pro-apoptotic proteins into the cytosol (33). In escin-treated 786-O cells stained with JC-1 dye, a concentration-dependent decrease in red fluorescence and an increase in green fluorescence were observed (Fig. 4B and C). This suggests that escin 
A

A
$\bar{\alpha}$
$\bar{\alpha}$

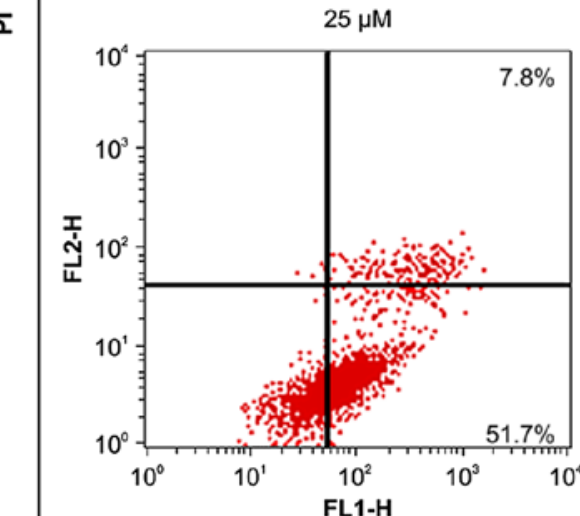

Control

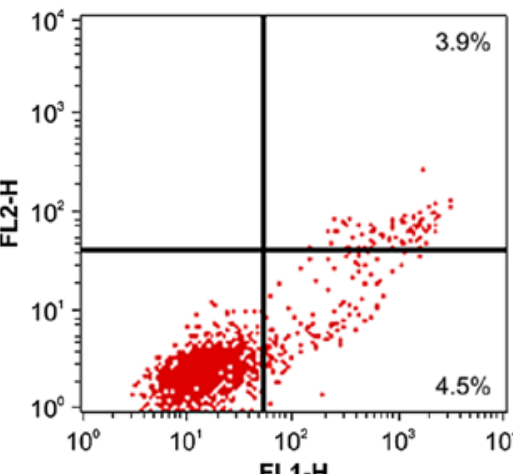

FL1-H

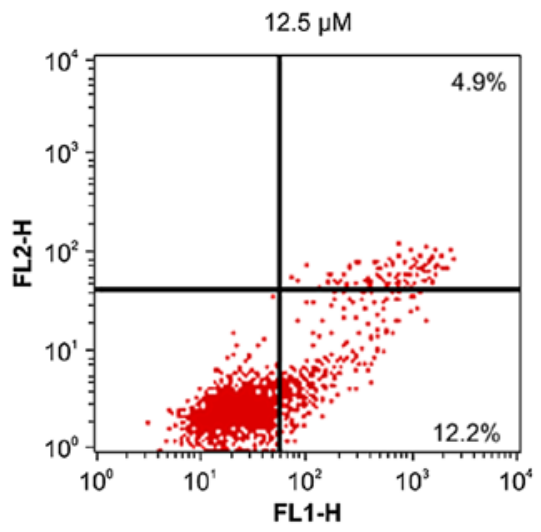

$50 \mu \mathrm{M}$

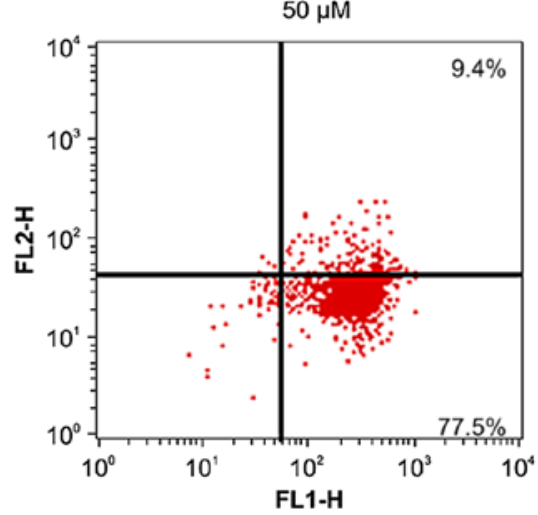

Annexin V

B

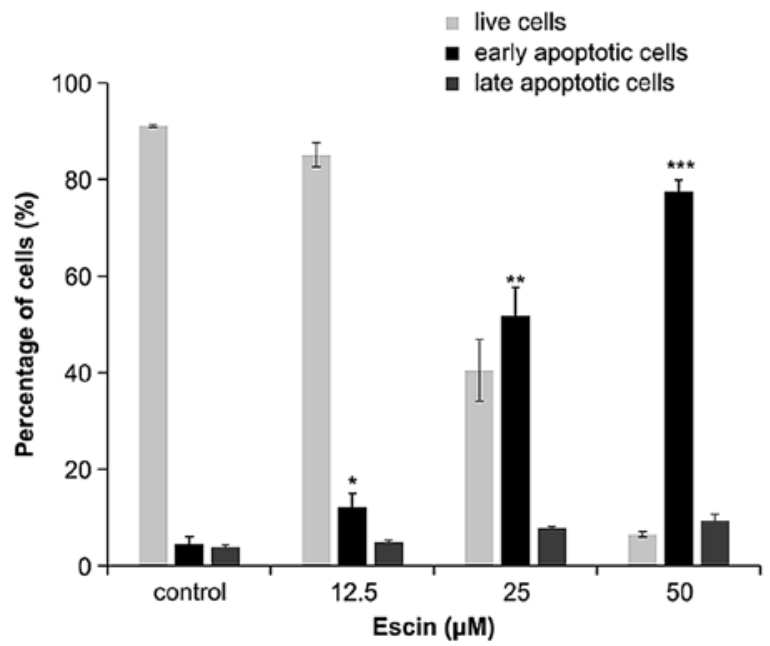

C

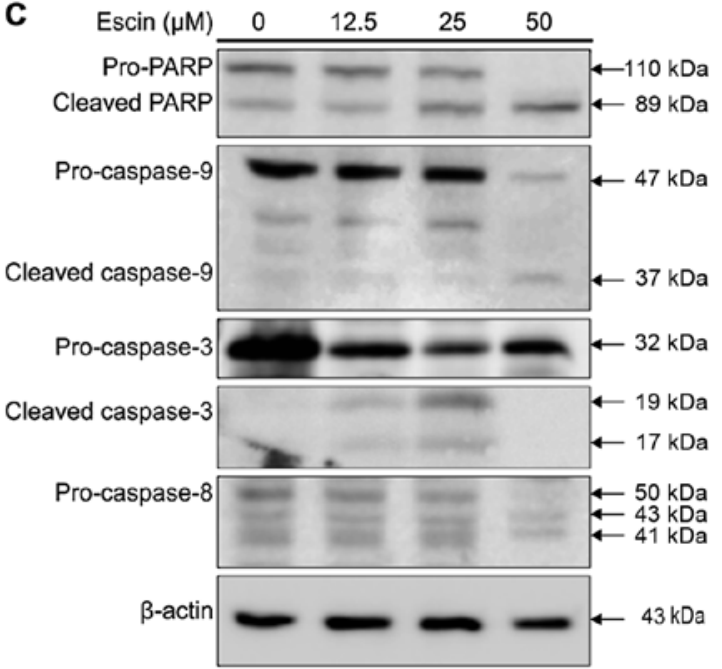

Figure 3. Flow cytometry analysis of escin-induced apoptosis in 786-O cells. (A) Effect of escin on Annexin V binding in 786-O cells. Cells were treated with 0, 12.5, 25 and $50 \mu \mathrm{M}$ escin for $16 \mathrm{~h}$. Subsequently, the treated cells were labelled with Annexin V-fluorescein isothiocyanate and PI. In each flow cytometry plot, the lower right quadrant (Annexin $\mathrm{V}^{+} / \mathrm{PI}$ ) shows early apoptotic cells, while the upper right quadrant $\left(\right.$ Annexin $\mathrm{V}^{+} / \mathrm{PI}^{+}$) depicts late apoptotic and necrotic cells. (B) The percentages of live, early apoptotic and late apoptotic cells were calculated and subjected to statistical analysis. Data are representative of three independent experiments. Statistical significance ${ }^{*} \mathrm{p}<0.05,{ }^{* *} \mathrm{p}<0.01,{ }^{* * *} \mathrm{p}<0.001$ as compared with control. (C) Effect of escin on caspase activation in the 786-O cells. 786-O cells were treated with $0,12.5,25$, and $50 \mu \mathrm{M}$ escin for $24 \mathrm{~h}$. Total cell lysates were resolved by sodium dodecyl sulphate-polyacrylamide gel electrophoresis (SDS-PAGE) and immunoblotted with antibodies against the cleaved forms of caspase- $9,-8$ and -3 , poly(ADP-ribose) polymerase (PARP) and $\beta$-actin. Data are representative of three independent experiments.

reduced $\Delta \Psi \mathrm{m}$. These results support the hypothesis that escin induces mitochondrial-mediated apoptosis in the renal cancer cells.

To further elucidate the mechanism of escin-induced mitochondrial-mediated apoptosis, we determined the effect of escin on the expression of Bcl-2 family proteins which regulate cytochrome $c$ release and caspase activity $(33,34)$. Specifically, we examined three $\mathrm{Bcl}-2$ family proteins, namely Bax, which promotes cytochrome $c$ release, and $\mathrm{Bcl}-2$ and Bcl-xL, both of which inhibit cytochrome $c$ release (33). As 
A
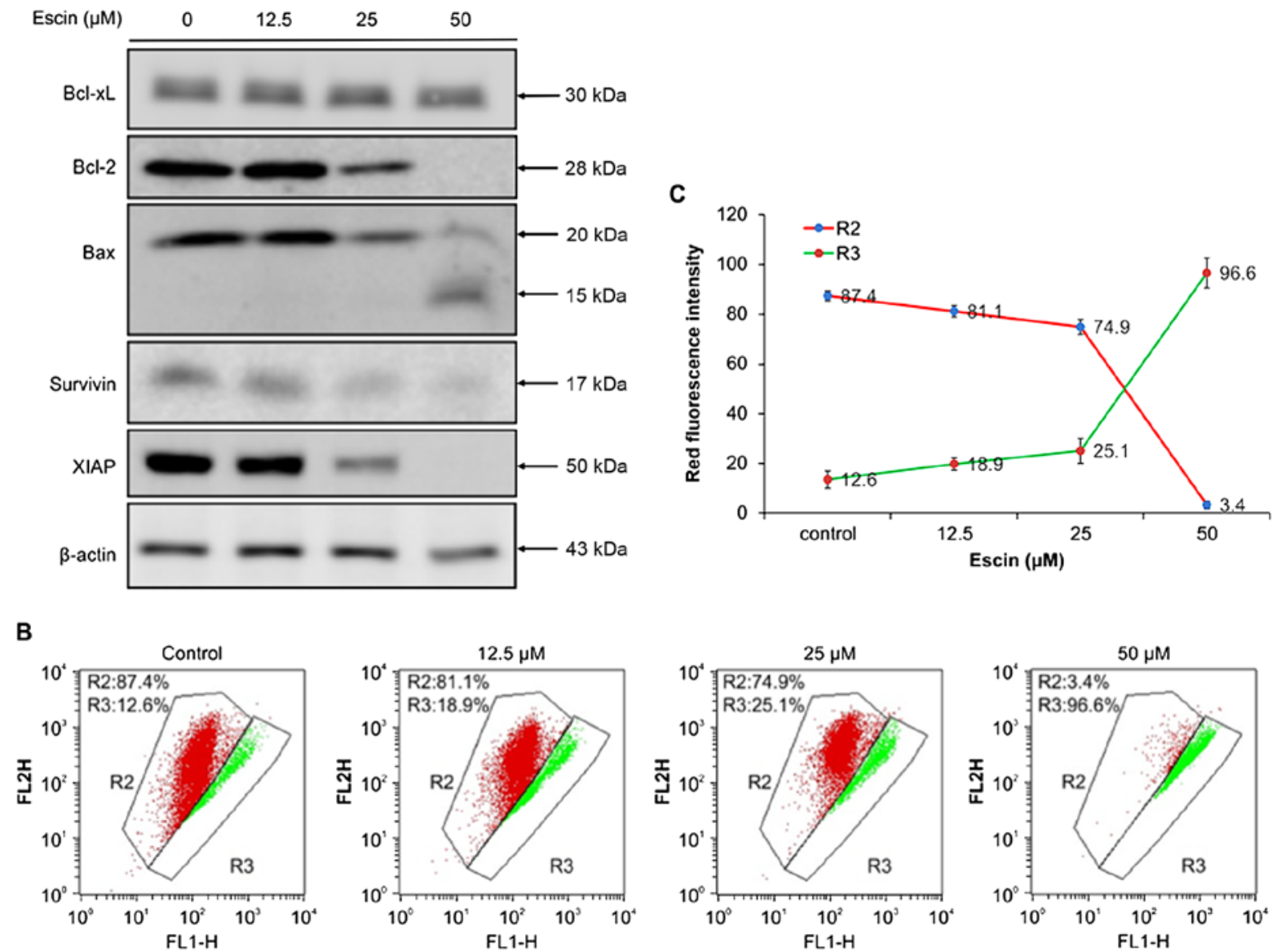

Figure 4. Effect of escin on mitochondrial-mediated apoptosis in 786-O cells. (A) Effect of escin on the expression of Bcl-2 family proteins and IAP protein in the 786-O cells. 786-O cells were treated with $0,12.5,25$ and $50 \mu \mathrm{M}$ escin for $24 \mathrm{~h}$. Cytosolic lysates of attached and floating cells were resolved by SDS-PAGE and then western blotted with anti-Bcl2, anti-Bcl-xL, anti-Bax, anti-XIAP, anti-survivin and anti- $\beta$-actin. (B) Effect of escin on the mitochondrial membrane potential. 786-O cells were treated with $0,12.5,25$ and $50 \mu \mathrm{M}$ escin for $24 \mathrm{~h}$, and then stained with JC-1 dye (R2, aggregated JC-1, red fluorescence; R3, monomeric JC-1, green fluorescence), and then the red:green fluorescence ratio, which indicates changes in the mitochondrial membrane potential, was measured by flow cytometry. (C) Effect of escin on depolarization of mitochondrial membrane potential. 786-O cells were treated with several concentrations of escin. JC-1 green fluorescence intensity relative to the red fluorescence intensity was measured in the 786-O cells.

shown in Fig. 4A, escin $(25$ and $50 \mu \mathrm{M})$ decreased the expression of Bcl-2 and increased the cleavage fragment (molecular mass; $15 \mathrm{kDa}$ ) of Bax, although the Bcl-xL protein level was unchanged in 786-O cells, which differed from the observed expression patterns of the other proteins. Furthermore, the levels of IAP proteins, including XIAP and survivin, which can bind to caspases-9/-3/-7 and prevent apoptosis, were significantly decreased (Fig. 4A). Taken together, these results suggest that escin induced mitochondrial-mediated apoptosis in the renal cancer cells by disrupting anti-apoptotic proteins that regulate the release of caspases and relieve downstream inhibition of apoptosis.

Escin-induced apoptosis is associated with ROS production. Since ROS can alter the cellular redox state and $\Delta \Psi \mathrm{m}(35,36)$, we investigated whether escin-treated $786-\mathrm{O}$ cells produce ROS. DHE staining revealed that red fluorescence intensity (Fig. 5A and B) and ROS production (Fig. 5C) increased in the 786-O cells treated with escin for $24 \mathrm{~h}$. In addition, DHE staining showed that the red fluorescence intensity was significantly increased in the 786-O cells treated at the indicated concentration $(\geq 12.5 \mu \mathrm{M})$ of escin (Fig. 5C). This indicates that ROS play a crucial role in escin-induced apoptosis in 786-O cells. Moreover, pretreatment of these cells with two antioxidants, NAC and GSH, reduced escin-induced cell apoptosis (Fig. 5D). Collectively, these results suggest that escin-induced mitochondrial-mediated apoptosis is associated with ROS production in renal cancer cells.

Escin does not induce death receptor-mediated apoptosis in 786-O cells. To ascertain whether escin induces extrinsic apoptosis, we determined the effect of escin on the expression of proteins involved in the death receptor pathway in 786-O cells. As shown in Fig. 6, treatment of 786-O cells with $>25 \mu \mathrm{M}$ escin did not increase but decreased expression of the Fas death receptor, Fas-L and Fas-associated death domain (FADD) protein levels as compared to those of internal control $\beta$-actin. These results support the hypothesis that escin does not induce death receptor-mediated apoptosis in renal cancer cells.

\section{Discussion}

Escin has been shown to have antitumor effects in various cancer cells both in vitro and in vivo $(21,37)$. However, the 

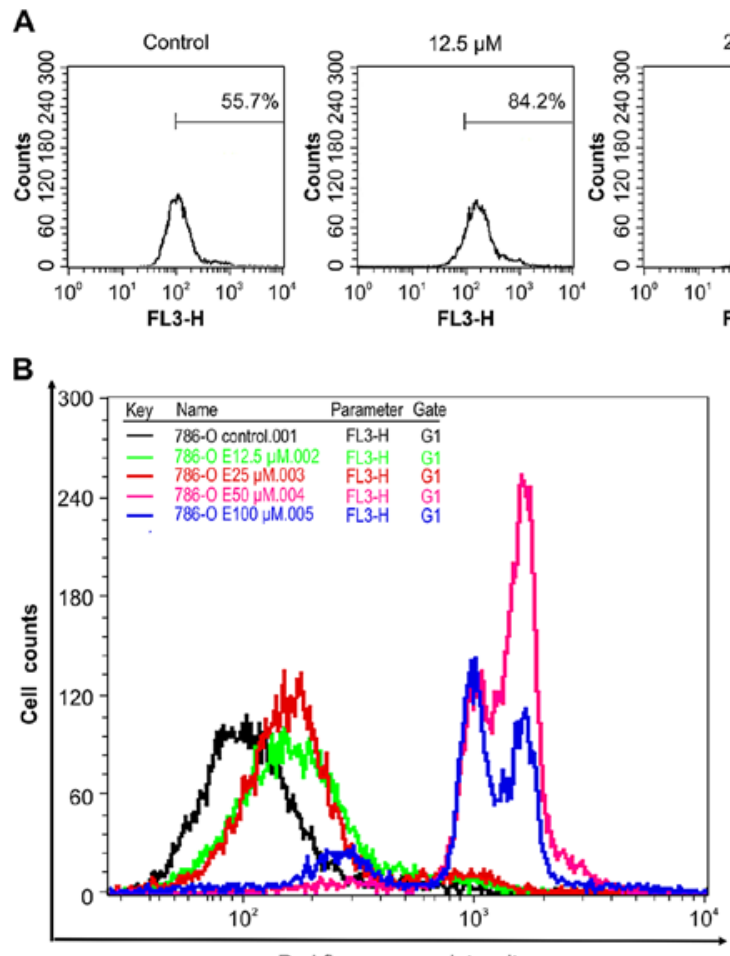

Red fluorescence intensity

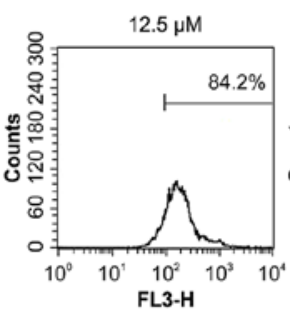

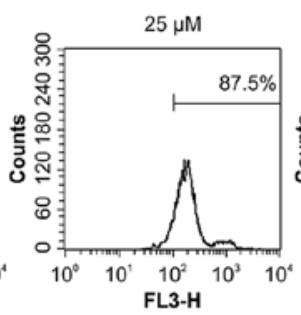
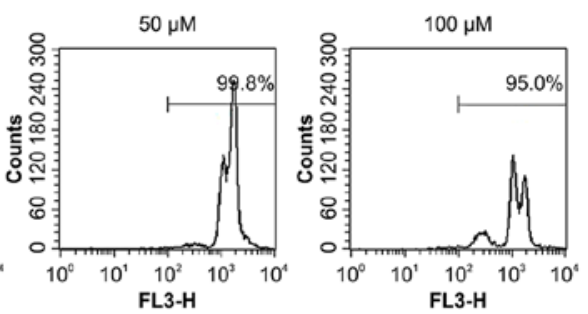

C
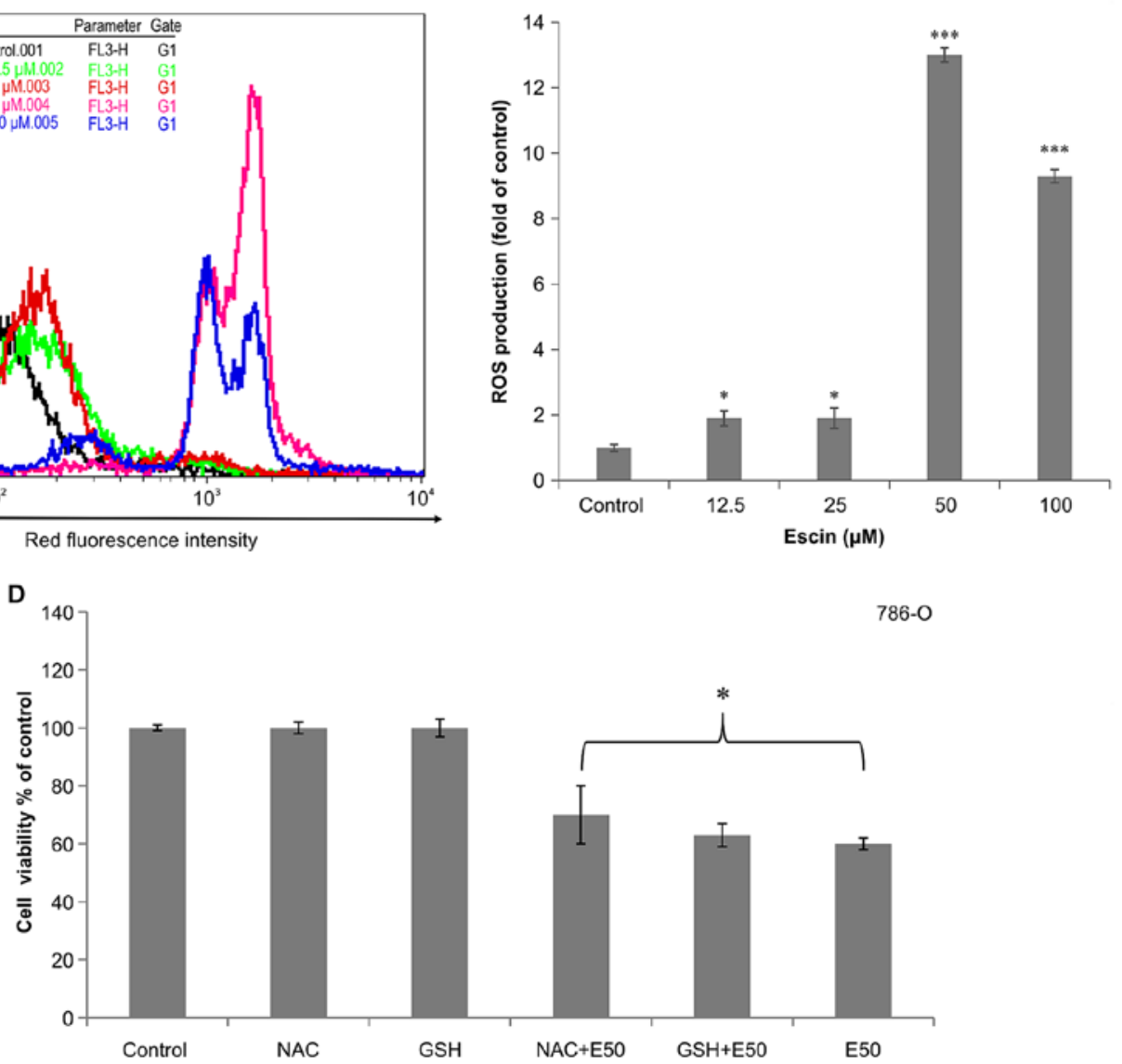

Figure 5. Effects of escin on reactive oxygen species (ROS) production and cell death in 786-O cells. (A and B) Cells were treated with several concentrations of escin for $24 \mathrm{~h}$. Escin-treated cells and vehicle-only control were stained with dihydroethidine (DHE), and then the intensity of red fluorescence was measured by flow cytometry. (C) Amount of ROS production in escin-treated cells relative to control cells was determined by DHE staining and expressed as fold-change relative to the ROS amount in 786-O control cells. Data are expressed as mean \pm SD of three independent experiments $\left({ }^{*} \mathrm{p}<0.05,{ }^{* * * *} \mathrm{p}<0.005\right)$. Red fluorescence intensity in the escin-treated cells relative to control cells was determined by FL3-H intensity. (D) Effects of $N$-acetyl-L-cysteine (NAC) and glutathione (GSH) antioxidants on ROS production in 786-O cells. Exponentially growing cells were pretreated with $10 \mathrm{mM} \mathrm{NAC} \mathrm{or} 10 \mathrm{mM}$ GSH for $2 \mathrm{~h}$. Subsequently, 786-O cells were treated with $50 \mu \mathrm{M}$ escin (E50) or DMSO (vehicle-only control) for $24 \mathrm{~h}$. The cell viability was detected with MTT assay. Cell viability in the cells treated with escin plus NAC was significantly increased as compared with that in the cells treated with escin alone. Data are expressed as mean $\pm \mathrm{SD}$ of three independent experiments $(" \mathrm{p}<0.05)$.

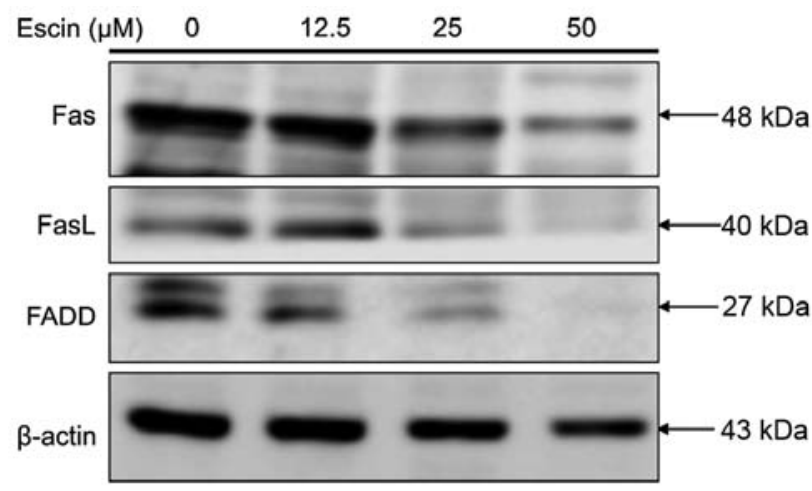

Figure 6. Effect of escin on the expression of three proteins involved in death receptor-mediated apoptosis in the 786-O cells. Cells were treated with 0 $12.5,25$ and $50 \mu \mathrm{M}$ for $24 \mathrm{~h}$. Whole-cell lysates were subjected to western blot analysis with antibodies against Fas, FasL, FADD and $\beta$-actin. 
molecular mechanisms by which escin exerts its antitumor effects on these cancer cells are largely unknown. For example, escin has been demonstrated to exhibit antitumor activities against human acute leukemia Jurkat T, HL-60, chronic myeloid leukemia K562, cholangiocarcinoma, hepatoma, colonic cancer, pancreatic and prostate cancer cells $(22-27,37,38)$. In the present study, we demonstrated for the first time that escin caused cell death or apoptosis in human renal cancer cells by inducing the intrinsic-mitochondrial apoptosis pathway involving $\mathrm{G} 2 / \mathrm{M}$ arrest and reactive oxygen species (ROS) generation.

Our results showed that escin was cytotoxic to human renal cancer cells (786-O and Caki-1) after a 24-h treatment with $\mathrm{IC}_{50}$ values of $40.6 \pm 1.2$ and $35.0 \pm 0.8 \mu \mathrm{M}$, respectively. However, this effect was more pronounced in the latter cell line Caki-1 ( $\left.\mathrm{VHL}^{+}\right)$. It is known that 786-O (VHL mutant) cell line is a malignant cancer with the faster growing rate than that of Caki-1 cells, and the $\mathrm{IC}_{50}$ value of escin for these cells was similar to that reported for human cholangiocarcinoma cells (QBC939) $(44.36 \pm 1.67 \mu \mathrm{M})(25)$. In the present study, we demonstrated that the protein level of cell cycle regulatory protein cdc-2 was significantly decreased following treatment with $25 \mu \mathrm{M}$ escin in the $786-\mathrm{O}$ cells. In addition, escin $(25 \mu \mathrm{M})$ caused cell cycle arrest at $\mathrm{G} 2 / \mathrm{M}$ transition in $786-\mathrm{O}$ cells. However, additional experiments involving cell cycle regulators, such as cyclin-dependent kinase $\mathrm{Cdc} 25 \mathrm{C}$, are needed to confirm these findings.

We also established that escin induced caspase-dependent apoptosis in the 786-O cells, and that the mitochondrial-mediated pathway is involved. Specifically, we showed that escin increased the percentage of early apoptotic cells (Fig. 3A and B), and decreased the mitochondrial membrane potential (Fig. 4B and C). We further demonstrated that escin increased the expression levels of several proteins that are important in apoptosis (32-34); escin concomitantly decreased the expression of anti-apoptotic proteins, such as Bcl-2, XIAP, survivin but increased the expression of proapoptotic protein, such as Bax cleavage (Fig. 4A), as well as downstream proteins, such as the cleaved forms of PARP and caspase-9 and -3 (Fig. 3C). Collectively, these results suggest that the cytotoxicity of escin to human renal cancer cells is mediated by multi-pronged intrinsic apoptotic pathways.

Furthermore, we demonstrated that escin-induced apoptosis in 786-O cells is associated with the production of ROS (Fig. 5A-C), which can be inhibited by antioxidants (Fig. 5D). This finding is consistent with several previous studies showing that escins induce production of ROS, loss of mitochondrial membrane potential, and caspase-dependent apoptosis in human cancer cells, such as cholangiocarcinoma cell lines (QBC939) (26) which is associated with the mitochondrial pathway. However, it is important to note that the balance in ROS levels can be markedly affected by many environmental factors including chemotherapeutic agents (35). ROS production is believed to reduce mitochondrial membrane potential, which in turn causes the release of cytochrome $c$ and initiates the apoptotic cascade (36). It is worth noting that, at higher concentrations, escin did not increase the expression of Fas, FasL, FADD or caspase-8, which are the components of the death-inducing signaling complex (Figs. 3C and 6). These results suggest that the death receptor pathway is not involved in the mechanisms of escin cytotoxicity. Another advantage of using escin is that it has low toxicity in human cells and has been used in folk medicine (39). In the present study, we demonstrated that escin exhibited no significant toxic effects on normal human PBMCs (Fig. 1B). Our results warrant further testing of escin as a chemotherapeutic agent for the treatment of renal cancer in human patients.

In conclusion, the results of the present study indicated that escin induced apoptosis in human renal cancer cells, by a mechanism involving the intrinsic-mitochondrial apoptosis pathway including G2/M arrest and ROS generation. These findings also suggest that escin may be a clinically valuable chemotherapeutic agent for the treatment of human renal cancer.

\section{Acknowledgements}

The present study was supported by the Taichung Veterans General Hospital and Hung Kuang University (grant no. TCVGH-HK1038003).

\section{References}

1. Znaor A, Lortet-Tieulent J, Laversanne M, Jemal A and Bray F: International variations and trends in renal cell carcinoma incidence and mortality. Eur Urol 67: 519-530, 2015.

2. Cheville JC, Lohse CM, Zincke H, Weaver AL and Blute ML: Comparisons of outcome and prognostic features among histologic subtypes of renal cell carcinoma. Am J Surg Pathol 27: 612-624, 2003.

3. Singer EA, Gupta GN and Srinivasan R: Update on targeted therapies for clear cell renal cell carcinoma. Curr Opin Oncol 23: 283-289, 2011.

4. Janzen NK, Kim HL, Figlin RA and Belldegrun AS: Surveillance after radical or partial nephrectomy for localized renal cell carcinoma and management of recurrent disease. Urol Clin North Am 30: 843-852, 2003.

5. Amato RJ: Chemotherapy for renal cell carcinoma. Semin Oncol 27: 177-186, 2000.

6. Hsu RJ, Ho JY, Cha TL, Yu DS, Wu CL, Huang WP, Chu P, Chen YH, Chen JT and Yu CP: WNT10A plays an oncogenic role in renal cell carcinoma by activating WNT/ $\beta$-catenin pathway. PLoS One 7: e47649, 2012.

7. Gurib-Fakim A: Medicinal plants: Traditions of yesterday and drugs of tomorrow. Mol Aspects Med 27: 1-93, 2006.

8. Cragg GM and Newman DJ: Natural products: A continuing source of novel drug leads. Biochim Biophys Acta 1830: 3670-3695, 2013.

9. Tutton PJ and Barkla DH: Influence of prostaglandin analogues on epithelial cell proliferation and xenograft growth. Br J Cancer 41: 47-51, 1980.

10. Stone OJ: Cancer resistance, carcinogenesis and ground substance viscosity. Med Hypotheses 20: 117-124, 1986.

11. Sirtori CR: Aescin: Pharmacology, pharmacokinetics and therapeutic profile. Pharmacol Res 44: 183-193, 2001.

12. Fu F, Hou Y, Jiang W, Wang R and Liu K: Escin: Inhibiting inflammation and promoting gastrointestinal transit to attenuate formation of postoperative adhesions. World J Surg 29: 1614-1620, 2005.

13. Diehm C, Trampisch HJ, Lange S and Schmidt C: Comparison of leg compression stocking and oral horse-chestnut seed extract therapy in patients with chronic venous insufficiency. Lancet 347: 292-294, 1996.

14. Bielanski TE and Piotrowski ZH: Horse-chestnut seed extract for chronic venous insufficiency. J Fam Pract 48: 171-172, 1999.

15. Rothkopf $M$ and Vogel G: New findings on the efficacy and mode of action of the horse chestnut saponin escin. Arzneimittelforschung 26: 225-235, 1976 (In German).

16. Matsuda H, Li Y, Murakami T, Ninomiya K, Yamahara J and Yoshikawa M: Effects of escins Ia, Ib, IIa, and IIb from horse chestnut, the seeds of Aesculus hippocastanum L., on acute inflammation in animals. Biol Pharm Bull 20: 1092-1095, 1997. 
17. Wang XH, Xu B, Liu JT and Cui JR: Effect of beta-escin sodium on endothelial cells proliferation, migration and apoptosis. Vascul Pharmacol 49: 158-165, 2008.

18. Kimura H, Ogawa S, Jisaka M, Kimura Y, Katsube T and Yokota K: Identification of novel saponins from edible seeds of Japanese horse chestnut (Aesculus turbinata BLUME) after treatment with wooden ashes and their nutraceutical activity. J Pharm Biomed Anal 41: 1657-1665, 2006.

19. Hu JN, Zhu XM, Han LK, Saito M, Sun YS, Yoshikawa M, Kimura Y and Zheng YN: Anti-obesity effects of escins extracted from the seeds of Aesculus turbinata BLUME (Hippocastanaceae). Chem Pharm Bull 56: 12-16, 2008.

20. Marhuenda E, Alarcón de la Lastra C and Martín MJ: Antisecretory and gastroprotective effects of aescine in rats. Gen Pharmacol 25: 1213-1219, 1994.

21. Wang YW, Wang SJ, Zhou YN, Pan SH and Sun B: Escin augments the efficacy of gemcitabine through down-regulation of nuclear factor- $\kappa \mathrm{B}$ and nuclear factor- $\kappa \mathrm{B}$-regulated gene products in pancreatic cancer both in vitro and in vivo. J Cancer Res Clin Oncol 138: 785-797, 2012.

22. Zhang Z, Gao J, Cai X, Zhao Y, Wang Y, Lu W, Gu Z, Zhang S and Cao P: Escin sodium induces apoptosis of human acute leukemia Jurkat T cells. Phytother Res 25: 1747-1755, 2011.

23. Niu YP, Wu LM, Jiang YL, Wang WX and Li LD: Beta-escin, a natural triterpenoid saponin from Chinese horse chestnut seeds, depresses HL-60 human leukaemia cell proliferation and induces apoptosis. J Pharm Pharmacol 60: 1213-1220, 2008.

24. Niu YP, Li LD and Wu LM: Beta-aescin: A potent natural inhibitor of proliferation and inducer of apoptosis in human chronic myeloid leukemia K562 cells in vitro. Leuk Lymphoma 49: 1384-1391, 2008.

25. Shen DY, Kang JH, Song W, Zhang WQ, Li WG, Zhao Y and Chen QX: Apoptosis of human cholangiocarcinoma cell lines induced by $\beta$-escin through mitochondrial caspase-dependent pathway. Phytother Res 25: 1519-1526, 2011.

26. Zhou XY, Fu FH, Li Z, Dong QJ, He J and Wang CH: Escin, a natural mixture of triterpene saponins, exhibits antitumor activity against hepatocellular carcinoma. Planta Med 75: 1580-1585, 2009.

27. Patlolla JM, Raju J, Swamy MV and Rao CV: $\beta$-Escin inhibits colonic aberrant crypt foci formation in rats and regulates the cell cycle growth by inducing p $21^{\text {waf } 1 / c i p 1}$ in colon cancer cells. Mol Cancer Ther 5: 1459-1466, 2006.

28. Xia Z, Bergstrand A, DePierre JW and Nässberger L: The antidepressants imipramine, clomipramine, and citalopram induce apoptosis in human acute myeloid leukemia HL-60 cells via caspase-3 activation. J Biochem Mol Toxicol 13: 338-347, 1999.
29. Bindokas VP, Jordán J, Lee CC and Miller RJ: Superoxide production in rat hippocampal neurons: Selective imaging with hydroethidine. J Neurosci 16: 1324-1336, 1996.

30. Satoh T, Numakawa T, Abiru Y, Yamagata T, Ishikawa Y, Enokido $\mathrm{Y}$ and Hatanaka $\mathrm{H}$ : Production of reactive oxygen species and release of L-glutamate during superoxide anion-induced cell death of cerebellar granule neurons. J Neurochem 70: 316-324, 1998.

31. Yuan SY, Cheng CL, Ho HC, Wang SS, Chiu KY, Su CK, Ou YC and Lin CC: Nortriptyline induces mitochondria and death receptor-mediated apoptosis in bladder cancer cells and inhibits bladder tumor growth in vivo. Eur J Pharmacol 761: 309-320, 2015.

32. Wyllie AH, Kerr JF and Currie AR: Cell death: The significance of apoptosis. Int Rev Cytol 68: 251-306, 1980.

33. Brunelle JK and Letai A: Control of mitochondrial apoptosis by the Bcl-2 family. J Cell Sci 122: 437-441, 2009.

34. Wu CS, Chen YJ, Chen JJ, Shieh JJ, Huang CH, Lin PS, Chang GC, Chang JT and Lin CC: Terpinen-4-ol induces apoptosis in human nonsmall cell lung cancer in vitro and in vivo. Evid Based Complement Alternat Med 2012: 818261, 2012.

35. Cheng SB, Wu LC, Hsieh YC, Wu CH, Chan YJ, Chang LH, Chang CM, Hsu SL, Teng CL and Wu CC: Supercritical carbon dioxide extraction of aromatic turmerone from Curcuma longa Linn. induces apoptosis through reactive oxygen species-triggered intrinsic and extrinsic pathways in human hepatocellular carcinoma HepG2 cells. J Agric Food Chem 60: 9620-9630, 2012.

36. Simon HU, Haj-Yehia A and Levi-Schaffer F: Role of reactive oxygen species (ROS) in apoptosis induction. Apoptosis 5: 415-418, 2000

37. Piao S, Kang M, Lee YJ, Choi WS, Chun YS, Kwak C and Kim HH: Cytotoxic effects of escin on human castration-resistant prostate cancer cells through the induction of apoptosis and G2/M cell cycle arrest. Urology 84: 982.e1-982.e7, 2014.

38. Rimmon A, Vexler A, Berkovich L, Earon G, Ron I and Lev-Ari S: Escin chemosensitizes human pancreatic cancer cells and inhibits the nuclear factor-kappaB signaling pathway. Biochem Res Int 2013: 251752, 2013.

39. Küçükkurt I, Ince S, Keleş H, Akkol EK, Avci G, Yeşilada E and Bacak E: Beneficial effects of Aesculus hippocastanum L. seed extract on the body's own antioxidant defense system on subacute administration. J Ethnopharmacol 129: 18-22, 2010. 